\title{
Analysis of LMP and TAP polymorphisms by polymerase chain reaction-restriction fragment length polymorphism in rheumatoid arthritis
}

\author{
J Vinasco, A Fraile, A Nieto, Y Beraun, E Pareja, L Mataran, J Martín
}

Instituto de Parasitología y Biomedicina "López

Neyra", CSIC, Granada, Spain J Vinasco

A Nieto

A Fraile

Y Beraun

J Martín

Sección de Biología Teórica, Hospital Virgen de las Nieves, Granada, Spain E Pareja

Servicio de Reumatología, Hospital Virgen de las Nieves, Granada, Spain

L Mataran

Correspondence to: Dr J Martín, Instituto de Parasitología y Biomedicina "Lopez-Neyra", C Ventanilla ${ }^{\circ} 1118001$ Granada, Spain.

Accepted for publication 22 September 1997

\begin{abstract}
Objective-The aim of this study was to investigate the relation between the polymorphism of large molecular weight proteasome (LMP) (LMP2-LMP7) and transporter associated with antigen processing (TAP) (TAP1-TAP2) genes and rheumatoid arthritis (RA).

Methods-Sixty RA patients and 102 ethnically matched unrelated healthy subjects were typed for LMP, TAP, and disease associated HLA-DRB1 alleles by using a new strategy based on polymerase chain reaction-restriction fragment length polymorphism (PCR-RFLP) with amplification created restriction sites.

Results-The polymorphism of LMP (LMP2-LMP7) and TAP (TAP1-TAP2) genes was examined in shared epitope positive and negative RA patients and controls. No significant differences in the LMP or TAP allele frequencies were observed between the total patient and control groups or the patients and controls positive or negative for the shared epitope.

Conclusion-The data suggest that the polymorphisms of LMP and TAP genes do not have an important influence in the pathogenesis of RA, although larger studies will be needed to provide more conclusive evidence on the role of these genes in RA. A new, highly reliable strategy for typing LMP alleles is also described.

(Ann Rheum Dis 1998;57:33-37)
\end{abstract}

Rheumatoid arthritis (RA) is a human leucocyte antigen (HLA) class II associated disease and HLA-DR alleles that are associated with RA across a variety of ethnic groups share a common sequence of amino acids (residues 70 to 74 ) in the third hypervariable region of the HLA-DR $\beta 1$ chain. This motif or epitope encoded by these alleles would determine RA susceptibility according to the "shared epitope hypothesis". However, numerous data have evolved to indicate that the association between the shared epitope and RA is incomplete and that susceptibility and outcome of RA might be controlled by multiple genes. ${ }^{23}$

Recent studies have identified a cluster of genes within the class II MHC region, which play an important part in the class I restricted antigen presentation pathway. ${ }^{4-7}$ Two such genes, large molecular weight proteasome (LMP) LMP2 and LMP7 encode two proteasome subunits, and are believed to be involved in the degradation of cytosolic proteins and generation of antigenic peptides. Two other genes in this region, transporter associated with antigen processing (TAP) TAP1 and TAP2, encoded subunits of a transporter that translocates peptides generated in the cytosol across the endoplasmic reticulum before the assembly of class I molecule.

The location of the genes encoding the LMPs and TAPs within the major histocompatibility complex (MHC), their polymorphic nature and their gamma interferon inducible expression are properties shared by most components involved in antigen presentation and were taken as evidence implicating LMPs and TAPs in antigen processing. ${ }^{8}$ There are some descriptions of antigen presentation by class II molecules utilising the endogenous presentation pathway followed by class I molecules. ${ }^{9}$ Additional data demonstrating defective class I expression on lymphoid cells in a number of autoimmune disease including class II associated diseases such as $\mathrm{RA},{ }^{10}$ support the hypothesis that the LMP and TAP proteins may play a part in class II restricted antigen presentation of disease relevant peptides derived from endogenous proteins. It is possible that individual variability (polymorphism) in structure or expression of these genes will affect its specificity, resulting in different sets of peptides derived from the same antigen being presented to $\mathrm{T}$ cells in different people. As LMP and TAP proteins are strongly related with the immune response to virus infection ${ }^{11}$ and there is evidence suggesting a role of virus in the pathogenesis of RA, ${ }^{12}$ they could be modulating susceptibility to or severity of RA, or both. LMP and TAP genes are therefore attractive candidates as additional RA susceptibility/severity factors.

\section{Methods}

SUBJECTS

Sixty patients with RA and 102 ethnically matched control individuals, who had been previously defined for HLA-DR disease associated alleles (-DR1,-DR4, and -DR10), were included in this study. ${ }^{13}$ Clinical and laboratory characteristics of these patients have been described in a previous publication ${ }^{13}$; they included: age at disease onset, mean disease duration, presence of rheumatoid nodules, presence of additional extra-articular manifestations, which included vasculitis and lung disease, and rheumatoid factor seropositivity. 
LNP2

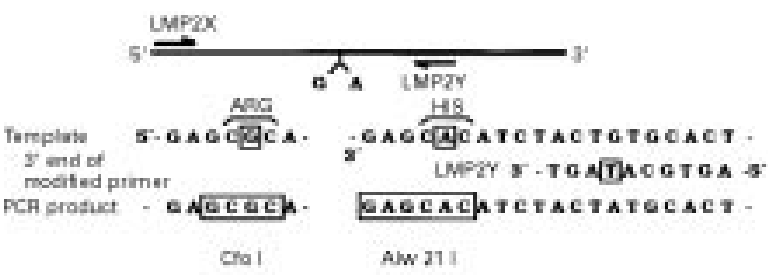

B LMP7

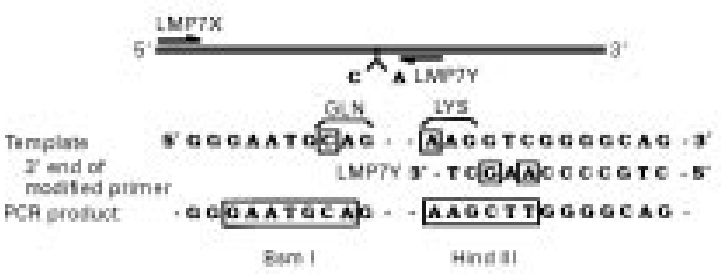

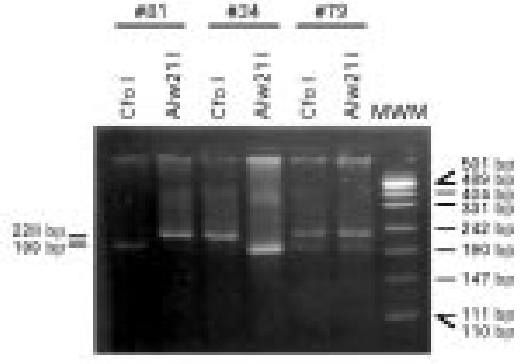

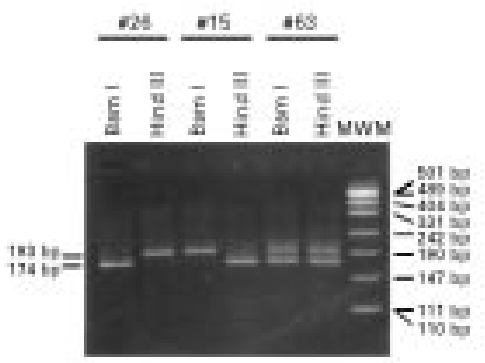

Figure 1 PCR-RFLP and amplification created restriction sites strategy for LMP2 (A) and LMP7 (B) typing. The position of the polymorphic base, localisation of the nucleotide mismatch in the oligonucleotide sequence and enzyme restriction site are indicated in boxes. Oligonucleotide sequences were as follows: LMP2X - 5'

CTTGAACCAGGGAGGCGAAGTTTG 3', LMP2Y - 5' CAGCTG AACCAGAGAGTGCATAGT 3'; LMP7X - 5' CGGACAGATCTCTGGGTGCT 3'; LMP7Y - 5'CTTCCCTACTGCCCCAAGCT 3'. (A) CfoI digestion generated a fragment of $199 \mathrm{bp}$ for LMP2-R allele while its homologue $L M P 2-H$ was undigested resulting in a 228 bp band. LMP2-H allele yielded a 199 bp fragment after Alw21I digestion while LMP2-R remain undigested. (B) BsmI and HindIII generated a 179 bp fragment for alleles LMP7-O and LMP7-K, respectively. The $193 \mathrm{bp}$ band represents the undigested product. Examples of each one of the three possible genotypes obtained in RA patients are shown. (A) LMP2 typing: \#81, LMP2-R/R; \#34, LMP2-H/H; \#79, LMP2-R/H. (B) LMP7 typing:\#26, LMP7-Q/Q;\#15, LMP7-K/K; \#63, LMP7-Q/K. Molecular weight marker (MWM):pUC19/MspI.

LMP2 AND LMP7 GENOTYPING DESIGN

The bi-allelic polymorphism at codon 60 (ArgHis) in the LMP2 gene was analysed by polymerase chain reaction-restriction fragment length polymorphism (PCR-RFLP) method using as primers LMP2X (forward) and LMP2Y (reverse), which amplify a $228 \mathrm{bp}$ fragment. The variant 60-Arg was typed for the presence of a restriction site for CfoI, as described previously. ${ }^{14}$ The variant 60 -His can be detected by the location of a restriction site for Alw21I. However, at eight bases 3' to this position we found a second recognition site for Alw21I, which is present in both alleles; therefore it could not be used for 60-His typing. To avoid this problem a modified primer was designed (LMP2Y), which destroys the shared Alw21I site, leaving intact the polymorphic site 60-Hist (fig 1A).

A recently described polymorphism at codon 145 (Lys-Gln) of the second exon in the LMP7 gene $^{14}$ was also analysed by PCR-RFLP. A fragment of $193 \mathrm{bp}$, that contains the LMP7 polymorphic site, was amplified using as primers LMP7X (forward) and LMP7Y (reverse). Variant $145-G \ln$ lies in a restriction site for BsmI. To analyse the variant $145-\mathrm{Lys}$, a modified primer (LMP7Y), was designed to create a restriction site for HindIII (fig 1B).

Genomic DNA was extracted from whole blood using a standard phenol/chloroform extraction before proteinase $\mathrm{K}$ digestion. DNA was amplified in $50 \mu \mathrm{l}$ reaction mixtures containing $0.2-0.5 \mu \mathrm{g}$ of genomic DNA using two units of thermostable DNA polymerase (DyNAZyme II) in the supplied $1 \times$ reaction buffer. Cycling conditions were as follows: $94^{\circ} \mathrm{C}$ for five minutes; 30 cycles of $94^{\circ} \mathrm{C}$ for one minute, $57^{\circ} \mathrm{C}$ of annealing temperature for 50 seconds in LMP2 amplifications and $62^{\circ} \mathrm{C}$ for 45 seconds in $\mathrm{LMP} 7,72^{\circ} \mathrm{C}$ for one minute; $72^{\circ} \mathrm{C}$ for 10 minutes. The amplified fragments were digested with the discriminating restriction enzymes for two to four hours. Cleavage of amplified fragments was detected by electrophoresis in $4 \%$ agarose gel ( $3 \%$ Nusieve, $1 \%$ Seakem. FMC, Rockland, ME, USA.)

HLA-DR4 AND -DR1 SUBTYPING, TAP1 AND TAP2 GENOTYPING

$\mathrm{DRB} 1^{\star} 04$ and $\mathrm{DRB}^{\star} 01$ subtyping was performed by the "allele walking" strategy. ${ }^{15}$ Typing for TAP alleles was performed using a method based on PCR-RFLP with amplification created restriction sites. ${ }^{16}$

STATISTICAL ANALYSIS

The significance level (p) was obtained by using the $\chi^{2}$ test or by Fisher's exact test, when appropriate. The $\mathrm{p}$ value was corrected $(\mathrm{pc})$ by use of the Bonferoni inequality method.

\section{Results}

The patients and controls were stratified in relation to positivity or negativity to shared epitope to minimise the possible linkage disequilibria between DRB1 and LMP or TAP 
Table 1 LMP2 and LMP7 genotype frequencies in RA patients and normal controls

\begin{tabular}{|c|c|c|c|c|c|c|}
\hline \multirow[b]{2}{*}{ LMP genotypes } & \multirow[b]{2}{*}{$\begin{array}{l}\text { Patients } \\
(n=60) n(\%)\end{array}$} & \multirow[b]{2}{*}{$\begin{array}{l}\text { Controls } \\
(n=102) n(\%)\end{array}$} & \multicolumn{2}{|c|}{ Positive for shared epitope } & \multicolumn{2}{|c|}{ Negative for shared epitope } \\
\hline & & & $\begin{array}{l}\text { Patients } \\
(n=35) n(\%)\end{array}$ & $\begin{array}{l}\text { Controls } \\
(n=44) n(\%)\end{array}$ & $\begin{array}{l}\text { Patients } \\
(n=25) n(\%)\end{array}$ & $\begin{array}{l}\text { Controls } \\
(n=58) n(\%)\end{array}$ \\
\hline LMP2-R/R & $35(58)$ & $56(55)$ & $20(57)$ & $29(66)$ & $15(60)$ & $27(46.5)$ \\
\hline LMP2-H/H & $1(2)$ & $3(3)$ & $1(3)$ & 0 & 0 & $3(5.2)$ \\
\hline LMP2-R/H & $24(40)$ & $43(42)$ & $14(40)$ & $15(34)$ & $10(40)$ & $28(48.3)$ \\
\hline LMP7-Q/Q & $48(80)$ & $91(89)$ & $28(80)$ & $36(81.8)$ & $20(80)$ & $55(94.8)$ \\
\hline LMP7-K/K & $2(3)$ & $3(3)$ & $1(3)$ & $3(6.8)$ & $1(4)$ & 0 \\
\hline $\mathrm{LMP} 7-\mathrm{Q} / \mathrm{K}$ & $10(17)$ & $8(8)$ & $6(17)$ & $5(11.4)$ & $4(16)$ & $3(5.2)$ \\
\hline
\end{tabular}

Table 2 TAP1 and TAP2 genotype frequencies in $R A$ patients and normal controls

\begin{tabular}{|c|c|c|c|c|c|c|}
\hline \multirow[b]{2}{*}{ LMP genotypes } & \multirow[b]{2}{*}{$\begin{array}{l}\text { Patients } \\
(n=60) n(\%)\end{array}$} & \multirow[b]{2}{*}{$\begin{array}{l}\text { Controls } \\
(n=61) n(\%)\end{array}$} & \multicolumn{2}{|c|}{ Positive for shared epitope } & \multicolumn{2}{|c|}{ Negative for shared epitope } \\
\hline & & & $\begin{array}{l}\text { Patients } \\
(n=35) n(\%)\end{array}$ & $\begin{array}{l}\text { Controls } \\
(n=28) n(\%)\end{array}$ & $\begin{array}{l}\text { Patients } \\
(n=25) n(\%)\end{array}$ & $\begin{array}{l}\text { Controls } \\
(n=33) n(\%)\end{array}$ \\
\hline $\mathrm{TAP} 1^{\star} \mathrm{A} / \mathrm{A}$ & $48(80)$ & $41(67.2)$ & $30(85.7)$ & $18(64.5)$ & $18(72)$ & $23(70)$ \\
\hline $\mathrm{TAP} 1 \star \mathrm{A} / \mathrm{C}$ & $3(5)$ & $1(1.6)$ & $1(2.9)$ & $1(3.5)$ & $2(8)$ & 0 \\
\hline $\mathrm{TAP} 1{ }^{\star} \mathrm{A} / \mathrm{D}$ & $1(1.7)$ & $3(5)$ & 0 & $1(3.5)$ & $1(4)$ & $2(6)$ \\
\hline $\mathrm{TAP} 1{ }^{\star} \mathrm{B} / \mathrm{C}$ & $1(1.7)$ & 0 & $1(2.9)$ & 0 & 0 & 0 \\
\hline $\mathrm{TAP} 1^{\star} \mathrm{D} / \mathrm{D}$ & 0 & $1(1.6)$ & 0 & 0 & 0 & $1(3)$ \\
\hline $\mathrm{TAP} 1{ }^{\star} \mathrm{F} / \mathrm{F}$ & 0 & $1(1.6)$ & 0 & $1(3.5)$ & 0 & 0 \\
\hline TAP1 NA* & $7(11.6)$ & $14(23)$ & $3(8.5)$ & 7 (25) & $4(16)$ & $7(21)$ \\
\hline $\mathrm{TAP} 2^{\star} \mathrm{A} / \mathrm{A}$ & $14(23.4)$ & $14(23)$ & $5(14.3)$ & $5(17.8)$ & $9(36)$ & $9(27.3)$ \\
\hline $\mathrm{TAP} 2{ }^{\star} \mathrm{A} / \mathrm{B}$ & 17 (28.4) & $15(24.6)$ & $11(31.4)$ & $8(28.5)$ & $6(24)$ & $7(21.2)$ \\
\hline $\mathrm{TAP} 2^{\star} \mathrm{A} / \mathrm{C}$ & $5(8.3)$ & $5(8.2)$ & $4(11.4)$ & $2(7.2)$ & $1(4)$ & $3(9)$ \\
\hline $\mathrm{TAP} 2^{\star} \mathrm{A} / \mathrm{D}$ & 0 & $1(1.6)$ & 0 & $1(3.6)$ & 0 & 0 \\
\hline $\mathrm{TAP} 2^{\star} \mathrm{A} / \mathrm{E}$ & $1(1.6)$ & $2(3.3)$ & $1(2.9)$ & $1(3.6)$ & 0 & $1(3)$ \\
\hline $\mathrm{TAP} 2{ }^{\star} \mathrm{A} / \mathrm{F}$ & $4(6.7)$ & $6(9.8)$ & $3(8.6)$ & $3(10.7)$ & $1(4)$ & $3(9)$ \\
\hline $\mathrm{TAP} 2 \star \mathrm{B} / \mathrm{B}$ & 7 (11.7) & $5(8.2)$ & $3(8.6)$ & $1(3.6)$ & $4(16)$ & $4(12.2)$ \\
\hline $\mathrm{TAP} 2{ }^{\star} \mathrm{B} / \mathrm{F}$ & $1(1.6)$ & $4(6.6)$ & $1(2.9)$ & $2(7.2)$ & 0 & $2(6.1)$ \\
\hline $\mathrm{TAP} 2{ }^{\star} \mathrm{C} / \mathrm{C}$ & $1(1.6)$ & $2(3.3)$ & $1(2.9)$ & 0 & 0 & $2(6.1)$ \\
\hline $\mathrm{TAP}^{\star}{ }^{\star} \mathrm{C} / \mathrm{D}$ & 0 & $1(1.6)$ & 0 & $1(3.6)$ & 0 & 0 \\
\hline TAP2 $\mathrm{NA}^{\star}$ & $10(16.7)$ & $6(9.8)$ & $6(17)$ & $4(14.2)$ & $4(16)$ & $2(6.1)$ \\
\hline
\end{tabular}

$\mathrm{TAP} 1{ }^{\star} \mathrm{A}, \mathrm{TAP} 1{ }^{\star} \mathrm{B}, \mathrm{TAP}{ }^{\star} \mathrm{C}, \mathrm{TAP} 1{ }^{\star} \mathrm{D}$ are identical to $\mathrm{TAP}{ }^{\star} 0101,{ }^{\star} 02011,{ }^{\star} 0301$ and ${ }^{\star} 0401$ respectively. $\mathrm{TAP} 2{ }^{\star} \mathrm{A}, \mathrm{TAP} 2^{\star} \mathrm{B}$, TAP $2{ }^{\star} \mathrm{E}, \mathrm{TAP} 2{ }^{\star} \mathrm{F}$ are identical to $\mathrm{TAP} 2{ }^{\star} 0101,{ }^{\star} 0201,{ }^{\star} 0102$ and ${ }^{\star} 0103$ respectively.

$\star \mathrm{NA}=$ not assigned.

genes. The DRB1 alleles carrying the shared epitope found in our population were as follows: DRB1*0401, 0404, 0405, 0408, 0101, 0102 and 1001 .

Table 1 shows the distribution of LMP2 and LMP7 genotype frequencies among RA patients and controls. No statistically significant differences appeared between the total patient and control groups. The increased frequency of the LMP7-Q/K genotype observed between patients and controls lacked statistical significance. Moreover, the frequency of the LMP2 and LMP7 genotypes was analysed in the subgroups of shared epitope positive or negative patients and controls. Increased frequencies of the $\mathrm{LMP} 2-\mathrm{R} / \mathrm{R}$ and $\mathrm{LMP} 7-\mathrm{Q} / \mathrm{K}$ genotypes were observed in the patients negative for the shared epitope compared with the shared epitope matched healthy controls, although the differences did not reach statistical significance.

Table 2 summarises the distribution of TAP genotype frequencies in RA patients and controls. As in other typing methods, the assignment of TAP1 and TAP2 genotypes in some heterozygotes was not possible because each dimorphic residue is analysed individually. No statistically significant differences were observed in the comparison of TAP1 and TAP2 genotype distribution between the patients with RA and the healthy controls. Again, no significant differences in the TAP1 and TAP2 genotype frequencies were observed between the patients positive or negative for the shared epitope and shared epitope matched healthy controls.

\section{Discussion}

In this study we describe a new strategy, based on PCR double RFLP with amplification created restriction sites, for LMP2 and LMP7 typing. This strategy, along with the previously designed one to type TAP alleles, ${ }^{16}$ was applied to identify LMP and TAP genotypes in our population. We found PCR-RFLP with amplication created restriction sites a favourable alternative to the several methods previously used to identify LMP and TAP polymorphisms. ${ }^{14-18}$ The most used typing methods, PCR-SSO and PRC-SSP depend on the differential hybridisation of short stretches of DNA, therefore the possibility of false positive or negative is possible when the conditions are not carefully adjusted. The strategy we designed has several advantages: restriction analysis is a potent tool to detect polymorphism, making false positive results very unlikely. Only positive results are taken into account to assign an allele, this is why the two variants at each polymorphic residue are assayed; the two results obtained must be congruent within themselves, in this way false negatives are practically avoided and the homozygosity of the sample tested unequivocally established. The use of amplification created restriction sites makes it possible to create or eliminate a restriction site when a natural one is not available or informative. Consequently, the results obtained for LMP and TAP alleles allows the totally reliable assignment of the genotypes of the samples studied. As in other typing methods using genomic DNA, it was not possible to assign TAP1 and TAP2 
alleles in people heterozygous at two or more polymorphic sites. To circumvent this problem we are currently analysing the possibility of applying the allele walking strategy ${ }^{15}$ on $\mathrm{cDNA}$ samples.

The location of polymorphic LMP and TAP genes in the HLA class II region and their function in antigen processing raises the question of the relation between the polymorphism of these genes and RA. It is interesting to note that a substitution in mouse LMP2 (Arg $\rightarrow$ $\mathrm{His}_{40}$ ) is identical both in position and identity of the substituted residues observed in human $\mathrm{LMP} 2^{19}$ and that preliminary findings suggest that this structural polymorphism may have functional consequences. ${ }^{20}$ We have not found any evidence of association between polymorphism in LMP2 and LMP7 genes and RA. In agreement with our present result, a previous study has failed to find an association between LMP polymorphism and RA. ${ }^{14}$ Thus, it is unlikely that LMP genes are significantly associated with RA, although further studies with larger numbers of patients are needed to confirm this. In addition to the previous study we have analysed our patient and control groups in relation to positivity or negativity of the shared epitope. Our negative findings are in contrast with previous work describing an association between LMP polymorphism and other autoimmune disease. ${ }^{21}$

Although no naturally occurring mutations in human TAP genes leading to a changed peptide transport specificity have been described so far, a recent study has shown that a single point mutation generated by site directed mutagenesis in TAP2 gene was sufficient to change the peptide transport specificity. ${ }^{22}$ The recently described variations in TAP1 (codon 648) and TAP2 (codon 651), which have not been studied in relation to their selectivity of transport, ${ }^{23}$ may have functional significance. This is the first report concerning an association between TAP genes, which includes the polymorphisms at codons 333637-648 of TAP1 and at codons 379-565-651665-687 of TAP2 and RA. Our analysis of the genetic polymorphism in the TAP genes in RA patients and healthy controls indicates that there was no association between TAP polymorphism and RA. Although several studies have analysed the association of TAP genes with RA, these reports have been limited to TAP2 ${ }^{24}{ }^{25}$ and they did not analyse the recently described polymorphism in TAP1 (codon 648) and TAP2 (codon 651). ${ }^{24-27}$ Our data confirm and extend the previous reports where no primary association between TAP alleles and RA was seen in different populations.

LMP and TAP genes could be modulating not susceptibility to RA but disease severity. Therefore, we examined the relation of LMP and TAP genotypes with clinical and laboratory parameters. Our preliminary data do not suggest a significant association of LMP2LMP7 or TAP1-TAP2 genotypes with any of these characteristics (data not shown). On the other hand, it would be possible, as recently proposed in AIDS, ${ }^{28}$ that combinations of HLA and TAP alleles may be important in the course of RA. Sample sizes must be larger than that used in this study, to convincingly evaluate the influence of these genes either individually or as extended haplotypes in the pathogenesis of RA.

In conclusion, the distribution of LMP2, LMP7, TAP1, and TAP2 alleles was determined using a new strategy we designed, based on PCR-RFLP and amplification created restriction sites, on patients with RA and controls. These results seem to rule out the relevance of LMP and TAP polymorphism in the pathogenesis of RA, although larger studies will be needed to provide more conclusive evidence on the role of these genes in RA.

This work was supported by SAF93-0021 and SAF97-0046 grants from Plan Nacional de I+D (CICYT). A Nieto has a fellowship from FIS $n^{\circ} 95 / 5333$. We thank C Oloriz for technical assistance and M Angel López-Nevot for his support.

1 Gregersen PK, Silver J, Winchester RJ. The shared epitope hypothesis. An approach to understanding the molecular genetics of susceptibility to rheumatoid arthritis. Arthritis Rheum 1987;30:1205-13

2 Wordsworth BP, Bell J. Polygenic susceptibility in rheumatoid arthritis. Ann Rheum Dis 1991;50:343-6.

3 McDaniel O, Alarcón GS, Pratt PW, Reveille JD. Most African-American patients with rheumatoid arthritis do not have the rheumatoid antigenic determinant (epitope). Ann Intern Med 1995;123:181-7.

4 Glynne R, Powis SH, Beck S, Kelly A, Kerr L, Trowsdale J. A proteasome-related gene between the two ABC trans-
porter loci in the class II region of the human MHC. Nature 1991;353:357-60.

5 Kelly A, Powis SH, Glynne R, Radley E, Beck S, Trowsdale J. Second proteasome-related gene in the human MHC J. Second proteasome-related gene in the
class II region. Nature 1991;353:667-8.

6 Troswdale J, Hanson I, Mockridge I, Beck S, Townsed A, Kelly A. Sequences encoded in the class II region of the MHC related to the "ABC" superfamily of transporters. MHC related to the "ABC

7 Spies T, Bresnahan M, Bahram S, Arnold D, Blanck G, Mellins E, et al. A gene in the human major histocompatbility complex region controlling the class I antigen presentation pathway. Nature 1990;348:744-7.

8 York IA, Rock KL. Antigen processing and presentation by the class I major histocompatibility complex. Annu Rev Immunol 1996;14:369-96.

9 Nuchtern JG, Biddison WE, Klauser RD. Class II MHC molecules can use the endogenous pathway of antigen presentation. Nature 1990;343:74-6.

10 Fu Y, Natham DM, Li F, Li X, Faustman DL. Defective major histocompatibility complex class I expression on lymphoid cells in autoimmunity. J Clin Invest 1993;91: 2301-7.

11 Lehner PJ, Cresswell P. Processing and delivery of peptides presented by MHC class I molecules. Curr Opin Immunol presented by $1996 ; 8: 59-67$.

12 Koide J, Takada K, Sugiura M, Sekine H, Ito T, Saito K, et al. Spontaneous establishment of an Epstein-Barr virusinfected fibroblast line from the synovial tissue of a rheumatoid arthritis patient. J Virol 1997;71:2478-81.

13 Vinasco J, Beraun Y, Nieto A, Fraile A, Mataran L, Pareja E, et al. Polymorphism at the TNF loci in rheumatoid arthritis. Tissue Antigens 1997;49:74-8.

14 Maksymowych WP, Tao S, Luong M, Suarez-Almanzor M, Nelson R, Pazderka F, et al. Polymorphism in the LMP2 and LMP7 genes and adult rheumatoid arthritis: no relationship with disease susceptibility or outcome. Tissue Antigens 1995; 46:136-9.

15 Nieto A, Martín J, Tobes R, Pareja E. "Allele walking": a new strategy to type HLA-DRB1 alleles. Tissue Antigens 1997;49:141-51.

16 Fraile A, Vinasco J, Nieto A, Pareja E, Martín J. Typing for TAP alleles using PCR-RFLP with amplification-created TAP alleles using PCR-RFLP with amplification-crion
restriction sites. Tissue Antigens 1996;47:346-52.

17 Colonna M, Bresnahan M, Bahram S, Strominger J, Spies T. Allelic variants of the human putative peptide transporter involved in antigen proccesing. Proc Natl Acad Sci USA 1992;89:3932-6.

18 Powis SH, Tonks S, Mockridge I, Kelly P, Bodmer JG, Trowsdale J. Alleles and haplotypes of the MHC-encoded ABC transporters TAP1 and TAP2. Immunogenetics 1993;37:373-80.

19 Nandi D, Iyer $M$, Monaco JJ. Characterization and polymorphism of the mouse MHC-linked Lmp-2 and Lmp-7 genes. Exp Clin Immunogenet 1996;13:20-9.

20 Monaco JJ, Nandi D, Marusina K, Iyer M, Jiang H. Function and polymorphism of MHC genes in class I antigen proccesing. In: Svejgaard A, Buus S, Fugger L. HLA gen proccesing. In: Svejgaard A, Buus S, Fugger L. HLA
and disease-the molecular basis. Copenhagen: Munksgaard,
1997: $91-6$.

21 Deng GY, Muir A, Maclaren NK, She JX. Association of LMP2 and LMP7 genes within the major histocompatibil- 
ity complex with insulin-dependent diabetes mellitus: population and family studies. Am J Hum Genet 1995;56: 528-34.

22 Armandola E, Momburg F, Nijenhuis M, Bulbuc N, Früh $\mathrm{K}$, Hämmerling G. A point mutation in the human transporter asociated with antigen processing (TAP2) alters the peptide transport specificity. Eur J Immunol 1996;26:1748-55.

23 Obst R, Armandola EA, Nijenhuis M, Momburg F, Hammerlin G. TAP polymorphism does not influence transport of peptide variants in mice and humans. Eur J Immunol 1995; 25:2170-6.

24 Marsal S, Hall MA, Panayi GS, Lanchbury JS. Association of TAP2 polymorphism with rheumatoid arthritis is secondary to allelic association with HLA-DRB1. Arthritis Rheum 1994;37:504-13.
25 Singal DP, Ye M, Qiu X, D'Souza M. Polymorphism in the TAP2 gene and their association with rheumatoid arthritis. TAP2 gene and their association with
Clin Exp Rheumatol 1994;12:29-33.

26 Wordsworth BP, Pile KD, Gibson K, Burney RO, Mockridge I, Powis SH. Analysis of the MHC-encoded transpoters TAP1 and TAP2 in rheumatoid arthritis: linkage with DR4 accounts for the association with a minor TAP2 allele. Tissue Antigens 1993;42:153-5.

27 Vandevyver C, Geusens P, Cassiman JJ, Raus J. Peptide transporter genes (TAP) polymorphism and genetic susceptibility to rheumatoid arthritis. $\mathrm{Br} J$ Rheumatol 1995;34:207-14.

28 Kaslow RA, Carrington M, Apple R, Park L, Muñoz A, Saah AJ, et al. Influence of combinations of human major histocompatibility complex genes on the course of HIV-1 infection. Nature Medicine 1996;2:4005-11. 